\title{
Preparation and Characterization of Proton Conductive Phosphosilicate Membranes Based on Inorganic-Organic Hybrid Materials
}

\author{
Sheng-Jian Huang, Hoi-Kwan Lee, and Won-Ho Kang* \\ Department of New Materials Science \& Engineering, Dankook University, Cheonan, Chungnam 330-714, Korea \\ *E-mail: wonhkang@dankook.ac.kr \\ Received November 15, 2004
}

\begin{abstract}
A series of proton conductive inorganic-organic hybrid membranes doped with phosphoric acid $\left(\mathrm{H}_{3} \mathrm{PO}_{4}\right)$ and/ or triethylphosphate $\left(\mathrm{PO}(\mathrm{OEt})_{3}\right)$ have been prepared by sol-gel process with 3-glycidoxypropyltrimethoxysilane (GPTMS), 3-aminopropyltriethoxysilane (APTES) and tetraethoxysilane (TEOS) as precursors. High proton conductivity of $3.0 \times 10^{-3} \mathrm{~S} / \mathrm{cm}$ with composition of 50TEOS-30GPTMS-20APTES-50H $\mathrm{PO}_{4}$ was obtained at $120{ }^{\circ} \mathrm{C}$ under $50 \%$ relative humidity. Thermal stability of membrane was significantly enhanced by the presence of $\mathrm{SiO}_{2}$ framework up to $250{ }^{\circ} \mathrm{C}$. XRD revealed that the gels are amorphous. IR spectra showed a good complexation of $\mathrm{H}_{3} \mathrm{PO}_{4}$ in the matrix. The conductivity under $75 \%$ relative humidity was significantly improved by addition of APTES due to the increase in concentration of defected site in hybrid matrix. The effect of $\mathrm{PO}(\mathrm{OEt})_{3}$, humidifying time, and heat-treatment were also investigated. $\mathrm{PO}(\mathrm{OEt})_{3}$ had no improvement on conductivity and conductivity increased with humidifying time, however, decreased with heating temperature.
\end{abstract}

Key Words : Proton conductivity, Phosphosilicate, Sol-gel process, Inorganic-organic hybrid, Fuel cells

\section{Introduction}

The inorganic-organic hybrid materials via sol-gel process have attracted great attentions in recent years because of their potential advantages over the conventional materials due to the combination of the inorganic and organic characteristic properties. ${ }^{1-3}$ From a practical point of view as the separators for fuel cells and sensors, these solid-state proton conductors have a promising future due to unique advantages such as flexibility, high mechanical strength, thermal stability and excellent processibility. Although the commercially used proton exchange membranes (PEMs), mostly based on per-fluorinated ionomer, such as Nafion ${ }^{\circledR}$ (Du Pont), Aciplex ${ }^{\circledR}$ (Asahi Chemicals), and Flemion ${ }^{\circledR}$ (Asahi Glass) families possess very desirable properties such as good mechanical strength, chemical stability and high conductivity. ${ }^{4}$ However, these membranes have their disadvantages: one is the high humidity dependence which limits the applications by the huge size (weight and volume) of the humidifier; the other one is the low $\mathrm{T}_{\mathrm{g}}$ (glass transition temperature) which restricts its application to a small operating temperature window blow $100{ }^{\circ} \mathrm{C} .5$ Furthermore, the existing membranes remain high fuel permeability, high cost, and poor hydrophilicity. Therefore, a new proton conductive material with excellent operating performance is required intensively. And solid state electrolyte for medium temperature $\left(100-200{ }^{\circ} \mathrm{C}\right)$ has been one of the new research issues due to higher $\mathrm{CO}$ tolerance and catalyst efficiency, ${ }^{6,7}$ better water and heat management.

Among recent researches, the inorganic-organic hybrid material is one of the most versatile ways due to the preformed and controllable properties by preparing inorganic and inorganic-organic proton conducting materials to be used as fillers for polymer composite membranes. ${ }^{8-10}$ The structure of them has been designed to possess fast proton as well as lithium ion conducing properties through mostly manipulating organic ligand to inorganic surface. Honma ${ }^{11,12}$ and co-workers have developed a series of hybrid materials via sol-gel process based on the $\mathrm{SiO}_{2}$ and low molecular weight polymers (polyethylene (PE); polyethylene oxide (PEO); polypropylene oxide (PPO); polytetramethylene oxide (PTMO)). These polymers were endcapped with alkoxysilane moieties. It was reported that continuous pathways for proton conduction could be set up in membrane matrix. However, the procedure is quite complicated and the resultant composites showed low chemical stability, especially when PEO was directly incorporated.

In the present study, the polymer phase was directly incorporated into the inorganic matrix through the epoxy ring-opening and polycondensation reactions of 3-glycidoxypropyltrimethoxysilane (GPTMS), with tetraethoxysilane (TEOS) as the starting precursors. We expect that the Si-O-Si backbone (provide thermal stability and mechanical strength, ${ }^{13}$ less swelling capacity) will be connected with each other by the pseudo PEO-chain (provide good flexibility and processibility) to form the nanocomposite materials. The microstructure is schematically represented in Figure 1. During the process, 3-aminopropyltriethosilane (APTES) was added into the precursor sol to shorten the gelation time. ${ }^{14,15}$ And water affinity will be expected due to the presence of nitrogen atoms with the oxygen atoms in PEO phase (atoms with unshared electrons are potential acceptors for hydrogen bonding ${ }^{16}$ ). APTES has been widely applied as coupling agent, employed in superficial coating and some porous hybrid matrix with functional amino group for metal catalysts. ${ }^{17-20}$ It was the first time we used for 
<smiles>CO[Si](C)(CCCOCC1CO1)OC</smiles><smiles>OCC(O)COCCCS(O)(O)O</smiles><smiles>COC[C@H](COCC[Si](O)(OC)OC)OCC(COCCC[Si](OC)(OC)OC)OCC(O)COCCC[Si](OC)(OC)OS(=O)(O)(OC)OC</smiles><smiles>CCC[Si](OC)(OC)O[Si](O)(OC)OC</smiles>

Figure 1. The schematic molecular structure of inorganic-organic hybrid membrane.

proton conductive materials. And the low cost phosphorous containing compounds, $\mathrm{H}_{3} \mathrm{PO}_{4}$ and/or $\mathrm{PO}(\mathrm{OEt})_{3}$, were doped to endow the membrane with proton conductivity.

\section{Experimental Section}

Preparation of hybrid membrane. The inorganicorganic hybrid membrane was fabricated at room temperature under atmospheric pressure by sol-gel process though hydrolysis and condensation of GPTMS (Acros, 97\%), TEOS (Acros, 98\%), and APTES (Acros, 99\%). $\mathrm{H}_{3} \mathrm{PO}_{4}$ $\left(85 \%\right.$ aqueous solution) and $\mathrm{PO}(\mathrm{OEt})_{3}$ (Sigma-Aldrich, $99.8+\%)$ were used as phosphorous dopants. All the chemicals were used as received. The whole synthetic process is showed in Figure 2. The total molar ratio of ethanol/Si was fixed to be 5 and water containing hydrochloric acid $(\mathrm{pH}=0.26)$ was added dropwise to the precursor solution, where $1 \mathrm{~mol}$ of total alkoxy groups in precursors met with $0.01 \mathrm{~mol}$ of $\mathrm{HCl}$ in $1 \mathrm{~mol}$ of $\mathrm{H}_{2} \mathrm{O}$ solution. The molar ratio of

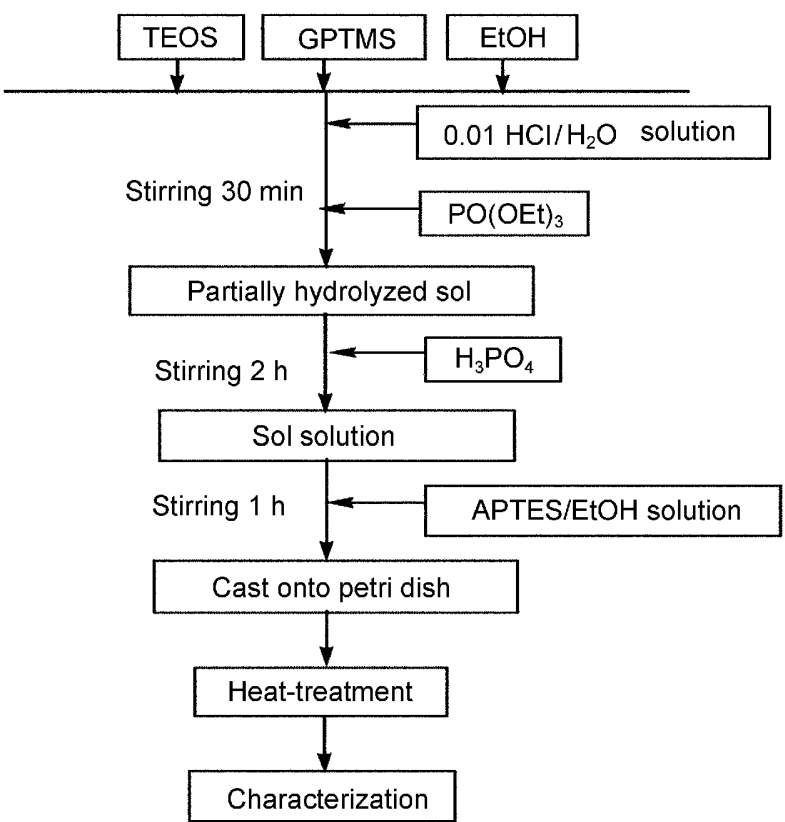

Figure 2. Synthetic procedure for the inorganic-organic hybrid membrane.

TEOS/GPTMS/APTES/ $\mathrm{H}_{3} \mathrm{PO}_{4} / \mathrm{PO}(\mathrm{OEt})_{3}$ was $50:(50-x): x$ : 50/y, where $x$ was varied from 0 to 30 , y from 0 to 200 . The sol obtained was cast onto Teflon mould, kept in oven $(\mu$ $251 \mathrm{R}$, Isuzu) at $60{ }^{\circ} \mathrm{C}$ for 1 days after sealing with plastic film, then the membrane was dried at $80{ }^{\circ} \mathrm{C}$ for 1 day open to air. The resultant membranes were heat-treated at a given temperature in a range of $120-250{ }^{\circ} \mathrm{C}$ for $2 \mathrm{~h}$ in air.

Analytical techniques. The proton conductivity was determined from Cole-Cole plot obtained with an impedance analyzer (HP4192A, Hewllett Packard) in a frequency range of $10 \mathrm{~Hz}-10 \mathrm{MHz}$. The silver paste was cast on both sides of the membrane as electrodes. All the impedance data were recorded after the resistance became constant for at least $2 \mathrm{~h}$ in a temperature-and humidity-controlled chamber. Experiments at different relative humidity levels were performed in a low temperature and humidity test chamber Isuzu). X-ray diffraction (XRD) patterns of gels were obtained with $\mathrm{Cu} \mathrm{K} \mathrm{K}_{\alpha}$ $(\lambda=0.154 \mathrm{~nm})$ radiation (XD-D1, Shimadzu). Morphologies of the gels were observed with a scanning electron microscope (SEM, JSM-5200, Jeol). Thermogravimetric (TG) analysis and differential thermal analysis (DTA) was performed with a heating rate of $10^{\circ} \mathrm{C} / \mathrm{min}$ in air (TG 8110 , Rigaku). Fourier transform infrared (FT-IR) spectra of gels were obtained on an infrared spectrophotometer (FTS3000MX, Bio-rad) with computer aid system.

\section{Results and Discussion}

Material appearance. Self-standing, flexible, and transparent membranes with thickness of 0.1-0.5 mm can be prepared easily. The flexibility increased with increasing GPTMS. However, when GPTMS increased, the membranes became more difficult to separate from the glass Petri dish due to the increasing adhesion to the dishes. ${ }^{21}$ When the 
glass dish was replaced by Teflon mould, the membrane with large area was readily separated from subtract and the drying time can also be shortening largely. Due to the high flexibility and proccessibility to make large area membrane with different thickness, this inorganic-organic membrane shows an advantage over inorganic phosphosilicate materials, which takes a long time to get thin film material preparing by sol-gel process.

The GPTMS/TEOS prehydrolyzed solution became opaque when APTES was added into the mixture and became transparent with a light brown as the gelation proceeded. The gelation time was largely shortened with the amount of APTES increased due to the $\mathrm{pH}$ change. In its absence, the polycondensation proceeded quite slowly, lasting several days instead of several hours. The result consisted with those of other researches. ${ }^{14,15}$ There was no deliquescence observed on the surface of the membranes after they were left in ambient condition for several days. It suggests that $\mathrm{H}_{3} \mathrm{PO}_{4}$ was incorporated quite well either in the PEO domain $^{22}$ or condensed silica domain, while the protons can dissociate from $\mathrm{H}_{3} \mathrm{PO}_{4}$ under humid condition to form conductive hydrated protons, such as $\mathrm{H}_{3} \mathrm{O}^{+}$and $\mathrm{H}_{5} \mathrm{O}_{2}^{+}$.

Characterization. Figure 3 shows the DTA-TG curves for hybrid membrane. In thermal curves, an endothermic peak from $57{ }^{\circ} \mathrm{C}$ to $129^{\circ} \mathrm{C}$ with a weight loss is observed. A weight loss less than $10 \mathrm{wt} \%$ before $200{ }^{\circ} \mathrm{C}$ is due to evaporation of physically absorbed water in the membrane. And the evaporation temperature of water is higher than 100 ${ }^{\circ} \mathrm{C}$, suggesting a good water affinity of membrane. On the other hand, three exothermic peaks at $310^{\circ} \mathrm{C}, 371{ }^{\circ} \mathrm{C}$, and $422{ }^{\circ} \mathrm{C}$ with a large weigh loss are seen, which should be attributed to the oxidation and/or decomposition of the side groups, side chains, and main chains in the polymer phase, respectively. Another two peaks at $664{ }^{\circ} \mathrm{C}$ and $1034{ }^{\circ} \mathrm{C}$ correspond to the $\mathrm{P}_{2} \mathrm{O}_{5}$ melting and $\mathrm{SiO}_{2}$ phase transformation, respectively. Thermal stability of the polymer phase in the membrane is highly enhanced by the nanolevel confinement of the inorganic $\mathrm{SiO}_{2}$ framework up to $250{ }^{\circ} \mathrm{C}$, suggesting a candidate electrolyte for medium temperature, especially for temperature at about $120-150^{\circ} \mathrm{C}$.

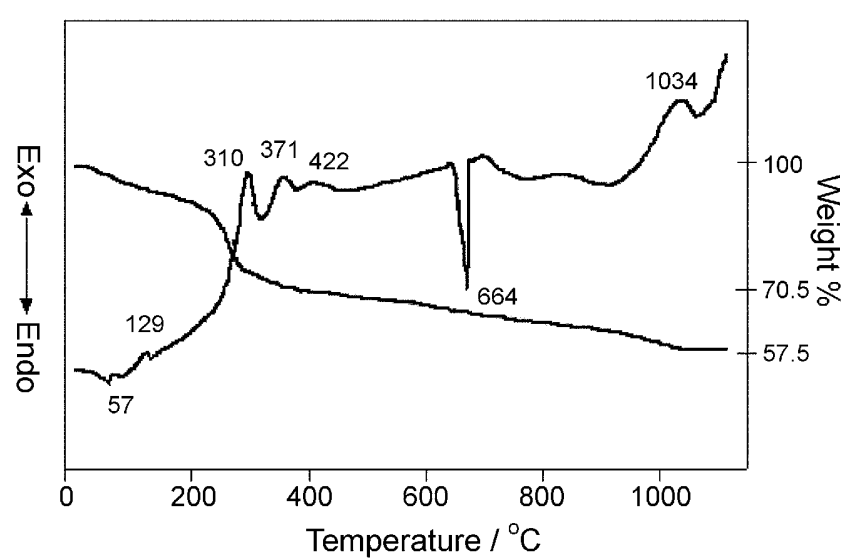

Figure 3. DTA-TG curves for sample 50TEOS-30GPTMS20APTES- $50 \mathrm{H}_{3} \mathrm{PO}_{4}$, which heat-treated at $120{ }^{\circ} \mathrm{C}$ for $2 \mathrm{~h}$.

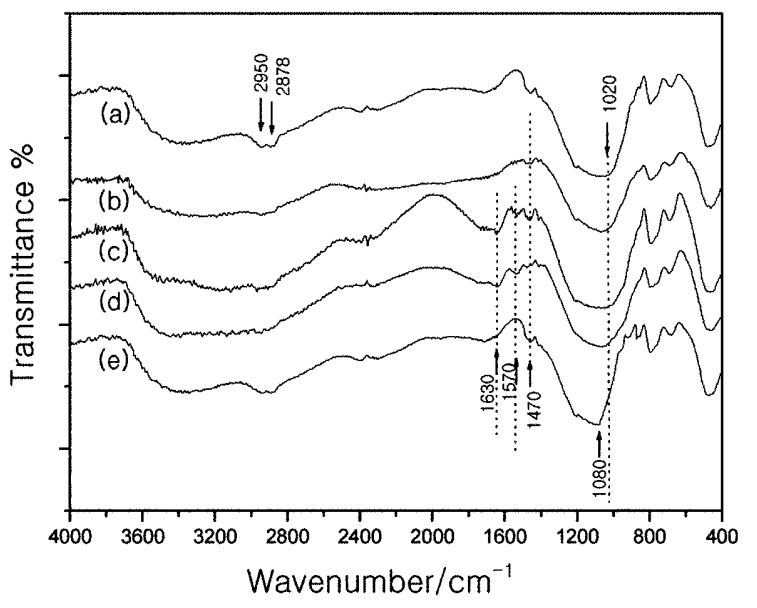

Figure 4. FT-IR spectra for samples heat-treated at $120{ }^{\circ} \mathrm{C}$ for $2 \mathrm{~h}$ : 50TEOS-(50-x) GPTMS- $x$ APTES- $50 \mathrm{H}_{3} \mathrm{PO}_{4}$, where $x=$ (a) 0 , (b) 5 , (c) 10 , (d) 20, respectively; and (e) 50TEOS-30 GPTMS20APTES.

Figure 4 compares the infrared spectra of membranes with various APTSES concentrations. Generally, in the wavenumber range from 400 to $1200 \mathrm{~cm}^{-1}$, pure silica shows several characteristic peaks. They are assigned to the Si-O$\mathrm{Si}$ and $\mathrm{Si}^{-} \mathrm{O}^{-}$stretching vibrations. With the addition of $\mathrm{H}_{3} \mathrm{PO}_{4}$, the absorption peak at $1080 \mathrm{~cm}^{-1}$ is broadened and shifted to lower wavenumber due to the presence of Si-O-P$\mathrm{O}$ bond $^{23}$ at $1020 \mathrm{~cm}^{-1}$. It suggests a complex between $\mathrm{H}_{3} \mathrm{PO}_{4}$ and $\mathrm{SiO}_{2}$ matrix. Absorption bands at 1470, 2878, and $2950 \mathrm{~cm}^{-1}$ are ascribed to $\mathrm{V}_{\mathrm{s}}\left(\mathrm{CH}_{2}\right), \mathrm{V}_{\mathrm{as}}\left(\mathrm{CH}_{2}\right)$ and $\delta\left(\mathrm{CH}_{2}\right)$, respectively. ${ }^{15}$ With APTES increasing, an absorption band at $1600 \mathrm{~cm}^{-1}$ due to deformation vibration of amino group, $-\mathrm{NH}_{2}$, split into $1525 \mathrm{~cm}^{-1}$ and $1633 \mathrm{~cm}^{-1}$, which assigns to deformation of $-\mathrm{NH}_{3}{ }^{+}$and $-\mathrm{NH}-$, respectively. ${ }^{17}$ The result obtained suggests interaction of amino groups with $\mathrm{H}_{3} \mathrm{PO}_{4}$ and /or epoxy ring. ${ }^{24}$ The broad absorption band at around $3400 \mathrm{~cm}^{-1}$ is relative to O-H stretching vibration, which is broadened and shifted to lower wavenumber with increasing APTES, suggesting an increase in water affinity.

Figure 5 shows the X-ray diffraction patterns of powder

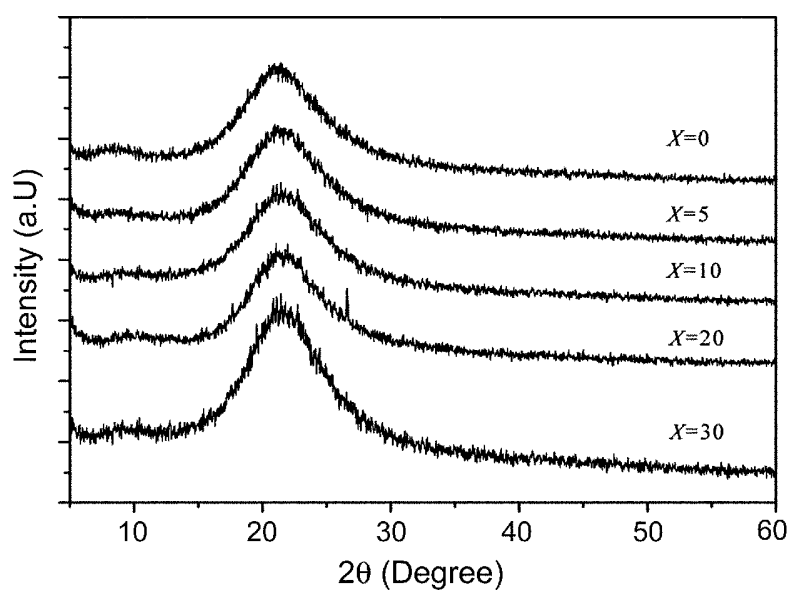

Figure 5. The XRD patterns for samples 50TEOS-(50- $x$ )GPTMS$x$ APTES- $50 \mathrm{H}_{3} \mathrm{PO}_{4}$, heat-treated at $120{ }^{\circ} \mathrm{C}$ for $2 \mathrm{~h}$. 

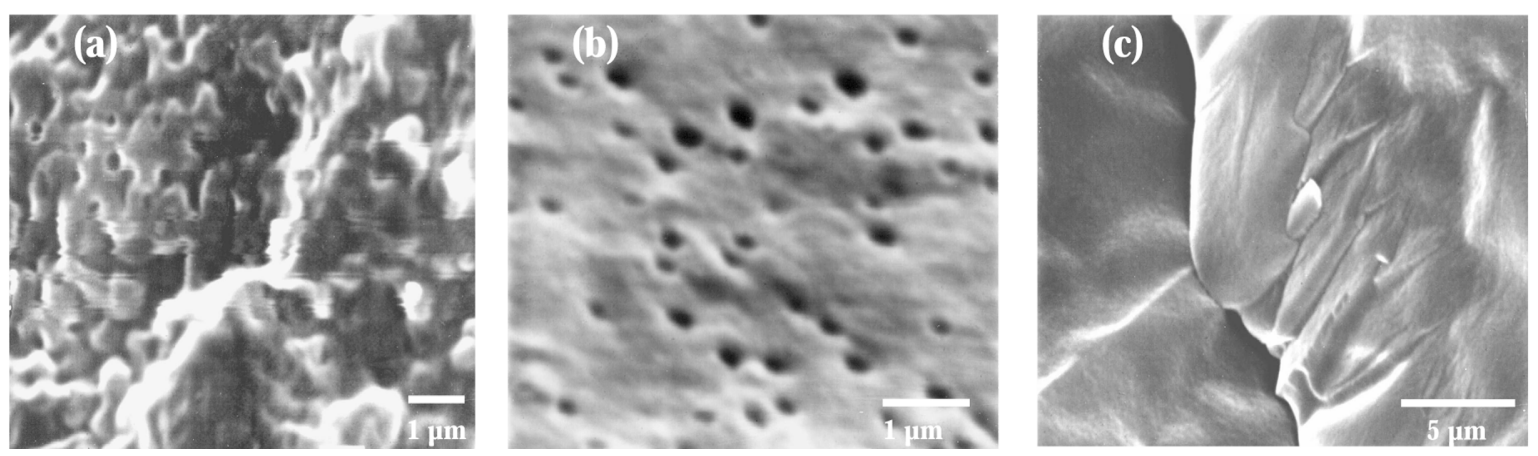

Figure 6. SEM images of hybrid membranes heat-treated at $120{ }^{\circ} \mathrm{C}$ for $2 \mathrm{~h}$ : (a) surface $(\times 10,000)$ of 50 TEOS-30GPTMS-20APTES$50 \mathrm{H}_{3} \mathrm{PO}_{4}$, (b)fractured section $(\times 20,000)$ of 50 TEOS-30GPTMS-20APTES-50H $\mathrm{H}_{3} \mathrm{PO}_{4}$, (c) partially fractured surface $(\times 5,000)$ of $50 \mathrm{TEOS}-$ 50 GPTMS- $50 \mathrm{H}_{3} \mathrm{PO}_{4}$.

samples with various APTES concentrations. No sharp diffraction peaks are observed, suggesting no crystallization for $\mathrm{Si}_{3}\left(\mathrm{PO}_{4}\right)_{4}$ or $\mathrm{SiHPO}_{4} \cdot 2 \mathrm{H}_{2} \mathrm{O}^{25,26}$ in the phosphosilicate matrix. A broad peak centers at about $2 \theta=21^{\circ}$ is the characteristic of vitreous $\mathrm{SiO}_{2}{ }^{27}$ Thus the hybrid is amorphous without long range ordering.

Figure 6 shows the morphology at the surface and fractured section of the hybrid membrane with $20 \mathrm{~mol} \%$ APTES, and partially fractured surface of membrane without APTES. As shown in Figure 6(a), irregular-shaped small particles having an edge of about $1 \mu \mathrm{m}$ are observed at the surface. These particles coated by the polymer matrix may ascribe to the inhomogeneous base-catalyzed polycondensation of APTES, resulting in rough particle and structure in the matrix. This is confirmed by the morphology at the fractured section, on which some small pores having a diameter of about 0.1-0.3 $\mu \mathrm{m}$ are observed. The reason for the coarser surface (Figure 6(a)) than that of fraction section (Figure 6(b)) may be the leaching of the small inorganic molecules on the surface due to humidity on the surface. It is inevitable that the small inorganic molecule will leach with water molecule on the surface during dehydration before SEM observation. In contrast, the membrane without APTES (Figure 6(c)) possessed a homogeneous texture at partially fractured surface. Thus it suggests that the pseudoPEO polymer networks have more 'defect' or broken bonds by the interruption of particles formed from APTES and/or terminal amino groups. As far as the textures observed by SEM are concerned, there are no through-holes in all of the examined membranes. Because of the microporous structure, swelling degree increased slightly with increasing APTES content (as shown in Figure 7), however, the mechanical strength is stable due to the rigid structure of $\mathrm{SiO}_{2}$.

Effect of APTES on conductivity. The chemical species which comprised the membranes matrix such as polyethylene oxide, silicate, and phosphoric acid are known as good insulators against electronic and/or hole conduction and their combination is understood to be very low possibility for further electron/ hole conduction. The conductive inorganicorganic hybrid membranes must be solely due to proton conductivity. These hybrid membranes can be regarded as a

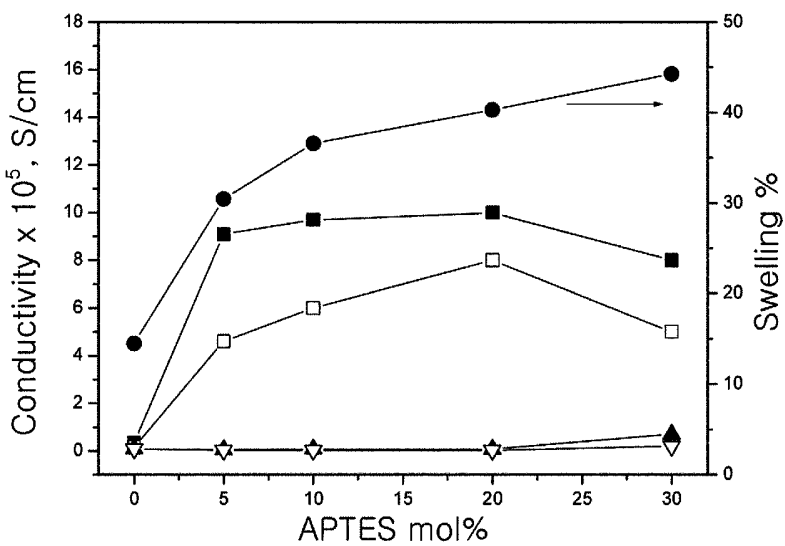

Figure 7. The comparison of conductivities under 5\%R.H $(\wedge, \nabla)$ and $75 \%$ R.H $(\boldsymbol{\square}, \square)$ at $60{ }^{\circ} \mathrm{C}$ as a function of various APTES concentrations. Close symbols represent the hybrid membranes without further heat-treatment at $120{ }^{\circ} \mathrm{C}$ for $2 \mathrm{~h}$. Open symbols represent the hybrid membranes with further heat-treatment at 120 ${ }^{\circ} \mathrm{C}$ for $2 \mathrm{~h}$. : The swelling index of samples heat-treated at 120 ${ }^{\circ} \mathrm{C}$ for $2 \mathrm{~h}$.

novel proton conductive hybrid material.

In the present study, the conductivities of all membranes show dependence on ambient humidity. When the relative humidity (R.H) was elevated from 5 to $75 \%$ R.H, the conductivities were increased largely, as seen in Figure 7. It strongly suggests the membranes are microporous in the matrix and able to absorb molecular water to favor the proton transportation. It is well known that the surface mechanism explains ${ }^{28,29}$ water-depended conduction in porous ceramic and glassy materials. According to this mechanism, water molecules are absorbed chemically and physically on the wide surface separating porous oxide and atmosphere. Under the low humidity, water molecules are chemisorbed quickly in the defected sites located on the surface presenting a high local charge density and a strong electrostatic field on exposure of the membrane to the atmosphere. And the amount of these molecules, once absorbed, is not further changed by exposure to the humidity. These active sites promote the water dissociation to provide protons as charge carriers: $2 \mathrm{H}_{2} \mathrm{O} \leftrightarrow \mathrm{H}_{3} \mathrm{O}^{+}+\mathrm{OH}^{-}$ of the hopping transporting mechanism known as 
Groutthuss chain reaction. ${ }^{30,31}$ When the hydronium $\left(\mathrm{H}_{3} \mathrm{O}^{+}\right)$ releases a proton to a neighbor water molecule, which accepts it while releasing another proton, charge transportation occurs. When the humidity increases, the subsequent water layers are physically adsorbed, condensed to form liquid water phase in the pores. The electrolytic conduction takes place along with proton transportation in the liquidlike phase.

As can be seen in Figure 7, conductivity, under 75\%R.H, of membrane further heated at $120{ }^{\circ} \mathrm{C}$ increases with increasing APTES, and shows a maximum at $20 \mathrm{~mol} \%$, while for membrane without further heat-treatment exhibits a Volcano type behavior with a maximum conductivity in the rang 5-20 mol\%. However, under low humidity (5\%R.H), conductivity is almost constant with increasing APTES, suggesting no obvious effect of the amino groups on conductivity. According to the mechanism mentioned above, we suppose that the incorporation of APTES increases the concentration of defected sites $\left(\equiv \mathrm{SiO}^{-}\right.$, ${ }^{+} \mathrm{H}_{3} \mathrm{NC}_{3} \mathrm{H}_{6}-\mathrm{Si} \equiv$ or $\left.\mathrm{H}_{2} \mathrm{PO}_{4}{ }^{-},{ }^{+} \mathrm{H}_{3} \mathrm{NC}_{3} \mathrm{H}_{6}-\mathrm{Si} \equiv\right),{ }^{15,32}$ which are necessary for water dissociation. According to Zhmud et al. ${ }^{15,33,34}$ the hydrogen bonds between amino groups and residual silanols (hydroxyl groups presents on the silica surface ) can arise from sprawling aminopropyl tails on the surface, ${ }^{33}$ as shown in Figure 1. And in the presence of water, this interaction promoted proton transfer from silanol to amino group, which leads to the formation of zwitterionslike moieties $\left(\equiv \mathrm{SiO}^{-},{ }^{+} \mathrm{H}_{3} \mathrm{~N}-\right)$ on the silica surface, and the amino groups can be protonated in acid medium. Thus high humidity condition favors not only the formation of defected sites but also the continuous paths by condensing water molecule to liquid-like phase, which is suitable for proton transportation on the pore surface. The swelling effect also showed the existence of the liquid water in the membrame and increase with increasing APTES.

On the other hand, since charge carrier is proton dissociated from the phosphoric acid, any factor to changing the concentration of $\mathrm{P}-\mathrm{OH}$ leads to the variation of proton conductivity of the membrane. Thus interaction of basic amino group $\left(-\mathrm{NH}_{2}\right)$ with acidic $\mathrm{P}-\mathrm{OH}$ group is the reason for decreasing in conductivity, resulting in a maximum conductivity at about $20 \mathrm{~mol} \%$ APTES as a compromise with the increase in defected sites and water content. However, the ion pair $\mathrm{H}_{2} \mathrm{PO}_{4}{ }^{-} \cdots{ }^{+} \mathrm{NH}_{3} \mathrm{C}_{3} \mathrm{H}$ is expected to increase the concentration of defected sites for water dissociation. It is noteworthy that the conductivity decreases with heating temperature, although the mechanical properties improve after further heating at $120{ }^{\circ} \mathrm{C}$ for $2 \mathrm{~h}$. The brittleness and solubility in water were also reduced obviously after the further polymerization of the silicate gels. The effect of heat-treatment will be discussed in latter section.

Temperature dependence of conductivity. Figure 8 shows the temperature dependence of conductivity of the hybrid membrane as measured under $50 \%$ R.H and plotted as a function of the reciprocal temperature. For comparison, conductivity of Nafion ${ }^{\mathbb{B}} 117$ membrane was also measured in

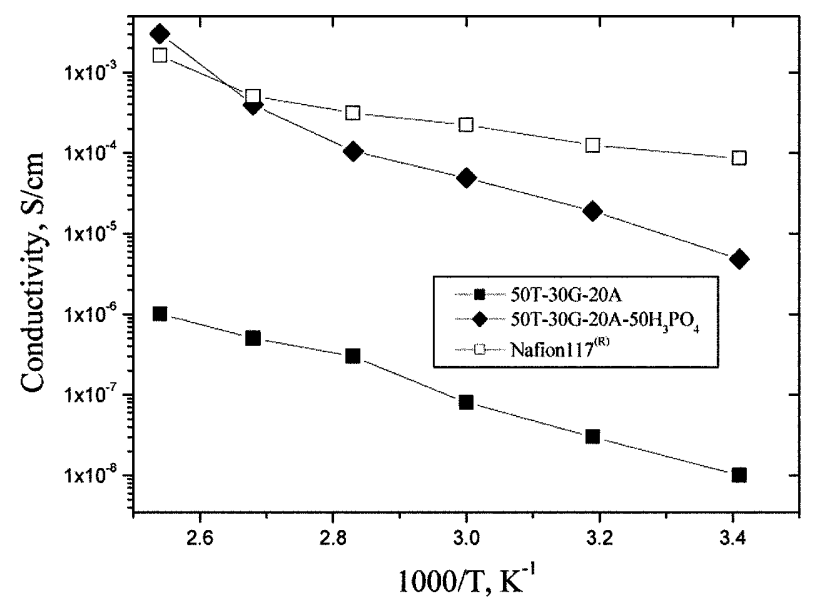

Figure 8. Temperature dependence of conductivity of membrane heat-treated at $120{ }^{\circ} \mathrm{C}$ for $2 \mathrm{~h}$. Conductivity was obtained under $50 \%$ R.H.

the same conditions as the fabricated hybrid membranes. The membrane 50T-30G-20A shows apparent proton conduction with a conductivity of $5.0 \times 10^{-7} \mathrm{~S} / \mathrm{cm}$ at $100{ }^{\circ} \mathrm{C}$ without addition of $\mathrm{H}_{3} \mathrm{PO}_{4}$. It strongly suggests that hybrid membrane with pseudo-PEO network has proton conductive property. By incorporating $\mathrm{H}_{3} \mathrm{PO}_{4}\left(50 \mathrm{~T}-30 \mathrm{G}-20 \mathrm{~A}-50 \mathrm{H}_{3} \mathrm{PO}_{4}\right)$, conductivity largely increases from $5.0 \times 10^{-7}$ to $3.9 \times 10^{-4}$ $\mathrm{S} / \mathrm{cm}$ at $100^{\circ} \mathrm{C}$, and then increases up to $3.0 \times 10^{-3} \mathrm{~S} / \mathrm{cm}$ as temperature increases to $120{ }^{\circ} \mathrm{C}$. These results confirmed that the proton conduction in the hybrid membranes originates primarily from the dissociation among the $\mathrm{H}_{3} \mathrm{PO}_{4}$ molecules doped in the membranes. ${ }^{35}$ The high conductivity close to Nafion ${ }^{\circledR} 117$ at $120{ }^{\circ} \mathrm{C}$ also suggested a better water affinity in the membrane at elevated temperature. It is notable that the plot of conductivity $(\sigma)$ versus reciprocal temperature $\left(\mathrm{T}^{-1}\right)$ is not exactly linear in the range from 20 to $120^{\circ} \mathrm{C}$, indicating the proton conduction does not just follow an Arrhenius-type behavior, but also shows the character of Vogel-Tamman-Fucher (VTF) behavior. It suggests that proton transportation in the $\mathrm{H}_{3} \mathrm{PO}_{4}$ system follows the Grotthuss mechanism, and $\mathrm{H}_{3} \mathrm{PO}_{4}$ dispersed among the hybrid framework shows the interaction with flexible PEO chains formed among GPTMS, indicating that the segmental motion plays a role in the proton conductivity.

Effect of $\mathrm{PO}(\mathrm{OEt})_{3}$ on conductivity. Trialkylphosphate, such as $\mathrm{PO}(\mathrm{OEt})_{3}$ has been used as phosphorous dopant in phosphosilicate ${ }^{23,36,37}$ and conduction has been found in these materials. However, hydrolysis rate of phosphate esters $\mathrm{PO}(\mathrm{OR})_{3}$ is very slow, while condensation rate of phosphoric acid at room temperature is very fast, especially at high phosphoric concentration, easily leading to congregation. For this reason, with the addition at 0.5 of molar ratio of phosphoric acid to silicon atom, the effect of $\mathrm{PO}(\mathrm{OEt})_{3}$ on conductivity has been investigated in present study. Figure 9 shows the effect of concentration of $\mathrm{PO}(\mathrm{OEt})_{3}$ on conductivity at $30{ }^{\circ} \mathrm{C}$ under $20 \%$ R.H, which the molar ratio of $\mathrm{PO}(\mathrm{OEt})_{3} / \mathrm{Si}$ was varied from 0 to 2.0 . As can be seen, the conductivity is maximized at 0.25 of molar ratio and then 


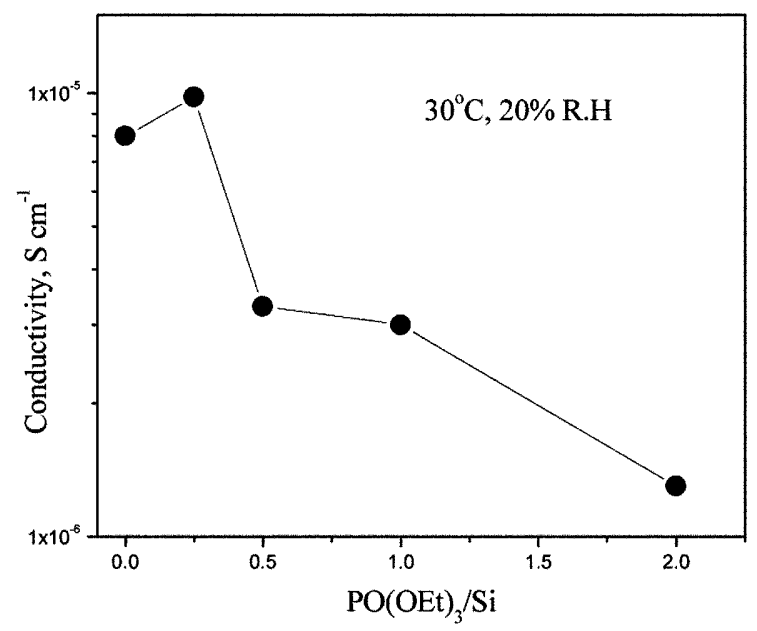

Figure 9. Effect of $\mathrm{PO}(\mathrm{OEt})_{3} / \mathrm{Si}$ molar ratio on conductivity of 50TEOS-30GPTMS-20APTES-50 $\mathrm{H}_{3} \mathrm{PO}_{4}-y \mathrm{PO}(\mathrm{OEt})_{3}$, which heattreated at $120{ }^{\circ} \mathrm{C}$ for $2 \mathrm{~h}$. y value varied from 0 to 2.0 and all the membranes were humidified at $30{ }^{\circ} \mathrm{C}$ under $70 \%$ R.H for $60 \mathrm{~h}$ before measurement.

decreases significantly at higher molar ratios. Although the hydrolysis of $\mathrm{PO}(\mathrm{OEt})_{3}$ increases the concentration of $\mathrm{P}-\mathrm{OH}$, its low hydrolysis rate during sol-gel process and heattreatment at lower temperature than $300{ }^{\circ} \mathrm{C}$ make few proportion of $\mathrm{PO}(\mathrm{OEt})_{3}$ added decompose into phosphoric acid. ${ }^{37}$ Thus the result indicates the gross effect of $\mathrm{PO}(\mathrm{OEt})_{3}$ addition is to reduce the relative concentration of phosphoric acid in the membrane. According to the thermal stability, the heating temperature of these membranes is limited lower than $250{ }^{\circ} \mathrm{C}$ in air, and its effect will be discussed later.

Effect of heat-treatment and humidifying on conductivity.To check out the effect of heat-treatment and humidifying time on conductivity, membrane with a composition as 50T-30G-20A-50 $\mathrm{H}_{3} \mathrm{PO}_{4}-25 \mathrm{PO}(\mathrm{OEt})_{3}$ was heated at 120 , 150 , and $200{ }^{\circ} \mathrm{C}$ for $2 \mathrm{~h}$ and then humidified at $30{ }^{\circ} \mathrm{C}$ under $70 \%$ R.H for various times before measurement. As can be seen in Figure 10, the conductivity decreases with increasing heating temperature at a given humidifying time, and conductivities get close after humidifying more than $130 \mathrm{~h}$. One reason for decrease in conductivity may be attributed to condensation of isolated phosphoric acid during heattreatment and more condensed phosphoric acid forms at higher heating temperature, ${ }^{37}$ resulting in decrease in concentration of $\mathrm{P}-\mathrm{OH}$ in membranes.

This can be confirmed by the XRD pattern, an inset in Figure 10. The crystalline $\mathrm{Si}_{3}\left(\mathrm{PO}_{4}\right)_{4}$ and $\mathrm{Si}\left(\mathrm{HPO}_{4}\right) \cdot 2 \mathrm{H}_{2} \mathrm{O}^{37}$ are observed when the heating temperature is elevated higher than $120{ }^{\circ} \mathrm{C}$. The other may be attributed to pore hindrance for water absorption. It is known that during the gelation and drying process, organic solvent and water molecule extract out of the matrix to form the micropores. The polymeric phase is readily to distribute on pores surface. When the temperature is elevated to near or over glass transition temperature $\left(\mathrm{T}_{\mathrm{g}}\right)$, the polymeric chains easily begin to readjust their conformations, leading to decrease in pore volume and even block the pores in the matrix.

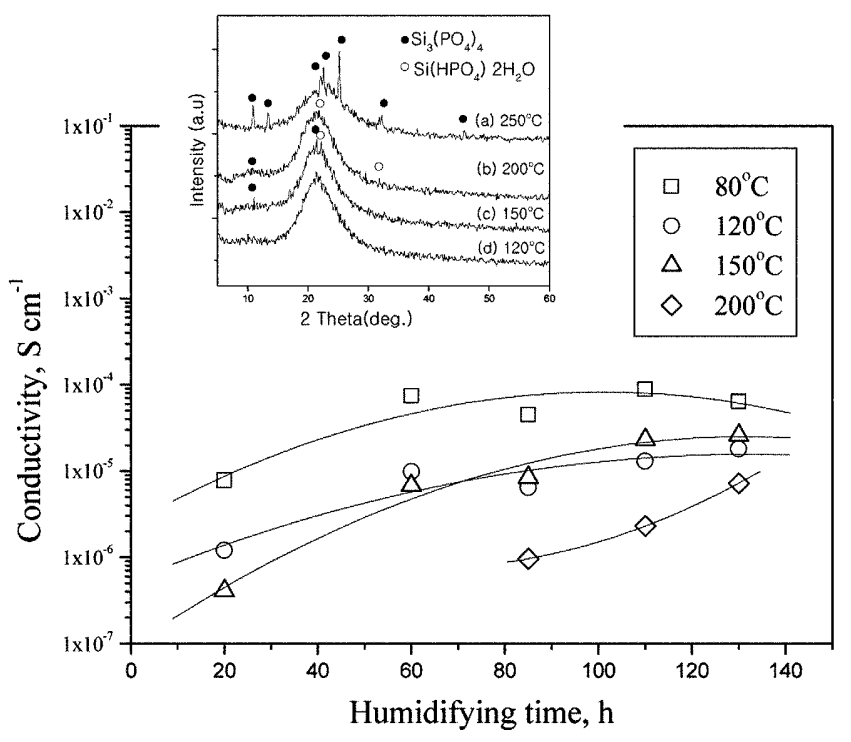

Figure 10. Dependence of proton conductivity on humidifying time at various heating temperatures. Humidifying conditions: 30 ${ }^{\circ} \mathrm{C}, 70 \%$ R.H. Squares, circles, triangles, and diamonds represent the membranes heat-treated at 80, 120, 150, and $200{ }^{\circ} \mathrm{C}$, respectively, for $2 \mathrm{~h}$. All resistances in Figs. 10 and 11 were obtained at $30{ }^{\circ} \mathrm{C}, 20 \%$ R.H with membrane 50TEOS-30GPTMS20APTES- $50 \mathrm{H}_{3} \mathrm{PO}_{4}-25 \mathrm{PO}(\mathrm{OEt})_{3}$.

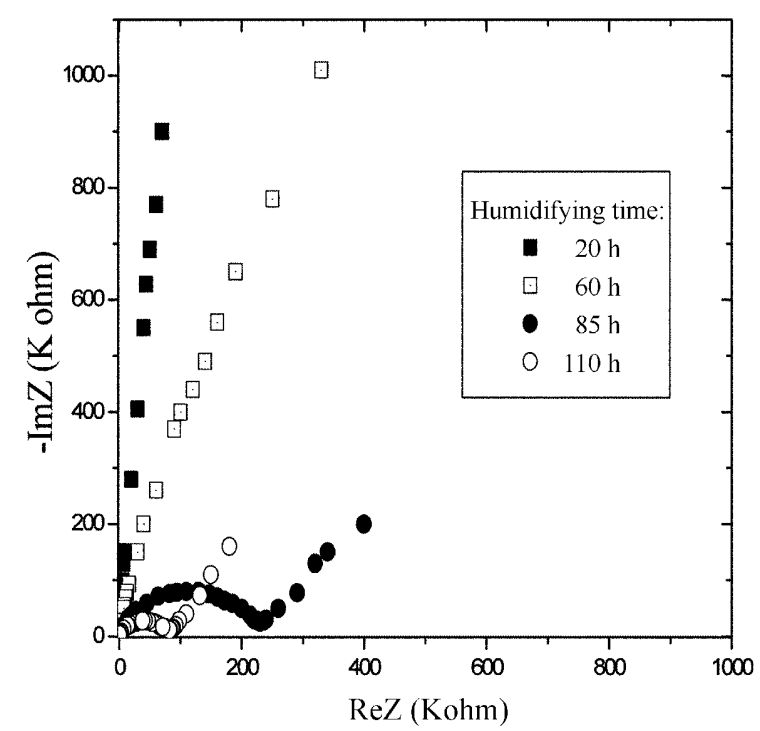

Figure 11. Complex impedance plots for membranes heat-treated at $200{ }^{\circ} \mathrm{C}$ with various humidifying time at $30{ }^{\circ} \mathrm{C}$ under $70 \%$ R.H. Bulk resistances were determined from the intercepts of the semicircle on the real axis.

Experiment about the pore property will be carried out in details later. Figure 10 also shows the effect of humidifying time on conductivity in a range of $20-130 \mathrm{~h}$ at $30^{\circ} \mathrm{C}$ under $70 \%$ R.H., and conductivities were obtained at $30{ }^{\circ} \mathrm{C}$ under low relative humidity $(20 \%$ R.H.) With humidifying time increasing, conductivities increase and level off after humidifying more than $60 \mathrm{~h}$ except for membrane heated at $200^{\circ} \mathrm{C}$. After heat-treating at $200{ }^{\circ} \mathrm{C}$, absorption of water molecule became more difficult and corresponding resistance 
decrease with humidifying time, as seen in Figure 11. These results suggest continuous paths suitable for fast proton conduction are formed due to the absorption of water molecule in the membranes heated at lower temperature.

\section{Conclusion}

A new inorganic-organic hybrid phosphosilicate membrane has been successfully prepared by sol-gel process through hydrolysis and condensation of GPTMS, APTES, and TEOS. The hybrid membrane doped with phosphoric acid shows good proton conductivity and is thermally stable up to $250^{\circ} \mathrm{C}$ in air due to the presence of tolerant inorganic $\mathrm{SiO}_{2}$ framework in the hybrid matrix. However, slight decrease in conductivity has also been observed with increasing heat temperature. With addition of APTES, not only the gelation time can be shortened, but conductivity is increased due to the increase in concentration of defected sites and water content due to porous structure. The flexible, transparent and homogenous membrane has humiditydepended conduction and its conductivity increases with increasing humidity. A high conductivity of $3.0 \times 10^{-3} \mathrm{~S} / \mathrm{cm}$ has been obtained at $120{ }^{\circ} \mathrm{C}$ under $50 \%$ R.H. The hybrid membrane can be potential to be used for medium temperature fuel cells and shows good processibility for large area membrane.

\section{References}

1. Brinker, C. J.; Scherrer, G. The Physics and Chemistry of Sol-Gel Processing, Sol-Gel Science; Academic Press: San Diego, 1990.

2. Judeinstein, P.; Sanchez, C. J. Mater. Chem. 1996, 6, 511.

3. Popall, M.; Andrei, M.; Kappel, J.; Kron, J.; Olma, K.; Olsowski, B. Electrochim. Acta 1998, 43, 155.

4. Savadogo, O. J. New Mater. Electrtochem. Syst. 1998, 1, 47.

5. Samms, S. R.; Wasmus, S.; Savinell, R. F. J. Electrochem. Soc. 1996, 143, 1498.

6. Malhotra, S.; Datta, R. J. Electrochem. Soc. 1997, 144, L23.

7. Alberti, G.; Casciola, M.; Palombari, R. J. Membr. Sci. 2000, 172, 233

8. Staiti, P.; Freni, S.; Hocevar, S. J. Power Sources 1999, 79(2), 250.
9. Alberti, G.; Casciola, M. Solid State Ionics 1997, 97, 177.

10. Bonnet, B.; Jones, J. et al. J. New Mater. Electrochem. Syst. 2000, 3,87 .

11. Honma, I.; Nomura, S.; Nakajima, H. J. Membr. Sci. 2001, 185, 83.

12. Honma, I.; Nakajima, H.; Nishikawa, O.; Sugimoto, T.; Nomura, S. Solid State Ionics 2003, 162-163, 237.

13. Oh, B. K.; Sun, Y. K.; Kim, D. W. Bull. Korean Chem. Soc. 2001, 22(10), 1136 .

14. Riegel, B.; Blittersdorf, S. et al. J. Non-Cryst. Solides 1998, 226, 76.

15. Zhmud, B. V.; Sonnefeld, J. J. Non-Cryst. Solides 1996, 195, 16.

16. Viart, N.; Rehspringer, J. L. J. Non-Cryst. Solides 1996, 195, 223.

17. Xia, H. P.; Pu, B. Y. et al. Chinese Science Bulletin 2000, 45(23), 2198.

18. Hook, D. J.; Vagro, T. G.; Gradella, J. A.; Litwiler, K. S.; Bright, F. V. Langmuir 1991, 7, 142.

19. Blaaderen, A. van; Vrij, A. J. Coll. Interf. Sci. 1993, 156, 1.

20. Zub, Yu. L.; Pechenyi, A. B.; Chuiko, A. A.; Stuchinskaya, T. L.; Kundo, N. N. Catal. Today 1993, 7, 31.

21. Hoebbel, D.; Nacken, M.; Schmidt, H. J. Sol-Gel Sci. Technol. 1998, $12(3), 169$.

22. Raducha, D.; Wieczorek, W.; Florjanczyk, Z.; Stevens, J.-R. J. Phys. Chem. 1996, 100, 20126.

23. Matsuda, A.; Kanzaki, T. et al. Solid State Ionics 2001, 139, 113.

24. Sforca, M. L.; Yoshida, I. V. P.; Nunes, S. P. J. Membr. Sci. 1999, 159, 197.

25. Lee, B. I.; Samuels, W. D.; Wang, L.-Q.; Exarhos, G. J. J. Mater. Res. 1996, 11, 134.

26. Hirata, K.; Matsuda, A.; Hirata, T.; Tatsumisago, M.; Minami, T. J. Sol-Gel Sci. Tech. 2000, 17(1), 61.

27. Nagai, M.; Kobayashi, K.; Nakajima, Y. Solid State Ionics 2000 , 136-137, 249

28. Kulwicki, M. B. J. Am. Ceram. Soc. 1991, 74, 697.

29. Garcia-Belmonte, G.; Kytin, V.; Bisquert, J. J. Appl. Phys. 2003, 54(8), 5261.

30. Bockris, M.; Reddy, A. K. N. Modern Electrochemistry; Plenum Press: N.Y., 1990; pp 461-448.

31. Lechner, R. E. Ferroelectrics 1995, 167, 83.

32. Etienne, M.; Walcarius, A. Talanta 2003, 59, 1173.

33. Golub, A. A.; Zubenko, A. I.; Zhmud, B. V. J. Colloid. Interf. Sci. 1996, 179, 482

34. Zhmud, B. V.; Pechenyi, A. B. J. Coloid. Interf. Sci. 1995, 173, 71.

35. Schechter, A.; Savinell, R. F. Solid State Ionics 2002, 147, 181.

36. Wang, C.; Nogami, M. Materials Letters 2000, 42, 225.

37. Matsuda, A.; Kanzaki, T.; Tatsumisago, M.; Minami, T. Solid State Ionics 2001, 145, 161. 